\title{
Neutrophils from severe asthmatic patients induce epithelial to mesenchymal transition in healthy bronchial epithelial cells
}

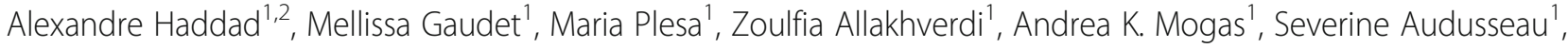
Carolyn J. Baglole ${ }^{1,2}$, David H. Eidelman ${ }^{1,2}$, Ronald Olivenstein ${ }^{1,2}$, Mara S. Ludwig ${ }^{1,2}$ and Qutayba Hamid ${ }^{1,2,3^{*}}$

\begin{abstract}
Background: Asthma is a heterogenous disease characterized by chronic inflammation and airway remodeling. An increase in the severity of airway remodeling is associated with a more severe form of asthma. There is increasing interest in the epithelial to mesenchymal transition process and mechanisms involved in the differentiation and repair of the airway epithelium, especially as they apply to severe asthma. Growing evidence suggests that Epithelial-Mesenchymal transition (EMT) could contribute to airway remodeling and fibrosis in asthma. Severe asthmatic patients with remodeled airways have a neutrophil driven inflammation. Neutrophils are an important source of TGF- $\beta 1$, which plays a role in recruitment and activation of inflammatory cells, extracellular matrix (ECM) production and fibrosis development, and is a potent inducer of EMT.
\end{abstract}

Objective: As there is little data examining the contribution of neutrophils and/or their mediators to the induction of EMT in airway epithelial cells, the objective of this study was to better understand the potential role of neutrophils in severe asthma in regards to EMT.

Methods: We used an in vitro system to investigate the neutrophil-epithelial cell interaction. We obtained peripheral blood neutrophils from severe asthmatic patients and control subjects and examined for their ability to induce EMT in primary airway epithelial cells.

Results: Our data indicate that neutrophils from severe asthmatic patients induce changes in morphology and EMT marker expression in bronchial epithelial cells consistent with the EMT process when co-cultured. TGF- $\beta 1$ levels in the culture medium of severe asthmatic patients were increased compared to that from co-cultures of nonasthmatic neutrophils and epithelial cells.

Conclusions and clinical relevance: As an inducer of EMT and an important source of TGF- $\beta 1$, neutrophils may play a significant role in the development of airway remodeling and fibrosis in severe asthmatic airways.

Keywords: Epithelial-mesenchymal transition, Airway remodeling, Severe asthma, Neutrophils, TGF- $\beta 1$

\section{Introduction}

Asthma, a complex heterogeneous disorder, with a broad spectrum of phenotypes, continues to increase globally and remains a major illness in terms of morbidity, mortality and cost (1). Asthma is classically considered an allergic, T-helper type $2\left(\mathrm{~T}_{\mathrm{H}} 2\right)$ cell driven inflammation, characterized by eosinophilic

\footnotetext{
* Correspondence: qutayba.hamid@mcgill.ca

${ }^{3}$ College of Medicine, University of Sharjah, Sharjah, United Arab Emirates

${ }^{2}$ Faculty of Medicine, McGill University, Montréal, Canada

Full list of author information is available at the end of the article
}

infiltration of the airway. Research has focused on the role of $\mathrm{T}_{\mathrm{H}} 2$ cells and cytokines (IL-4, IL-5, and IL-13) in contributing to asthma pathogenesis (2). However, subgroups of asthmatic patients with a more severe form of the disease exhibit refractory symptoms, with little to no eosinophil infiltration of the airway. The airway inflammation in severe asthma, which differs from mild or moderate persistent asthma, is characterized by the influx of neutrophils in sputum, bronchoalveolar lavage fluid (BALF) and biopsy specimens, with or without eosinophilia (1, 3-5). Airway 
neutrophilia has been shown to be associated with more severe airflow obstruction, lower lung function and thicker airway walls (6-8).

Airway remodeling is an important pathologic feature of asthma, and occurs in both the central and peripheral airways (9). The airway structural changes include injury and shedding of airway epithelium, enlargement of goblet cell and submucosal glands, increased myofibroblast number, subepithelial fibrosis, increased airway smooth muscle (ASM) mass and neovascularization (10-14). These changes contribute to the thickening of airway walls, increased mucus secretion and airway hyperresponsiveness and thereby lead to airway narrowing and airflow obstruction. The extent of airway remodeling is positively correlated with disease severity.

These changes, especially sub-epithelial fibrosis, may play an important role in disease pathogenesis and physiologic dysregulation. Chronic inflammation is believed to be the major contributor to airway remodeling in asthma via ongoing activation of inflammatory cells such as eosinophils, mast cells, T-cells and neutrophils. Substantial effort has been dedicated to trying to better understand and describe the mechanisms by which inflammation leads to airway remodeling. One mechanism which may play a significant role in airway remodeling is epithelial-mesenchymal transition (EMT).

During EMT, epithelial cells lose their apicalbasolateral polarity and cell-cell adhesions and acquire a mesenchymal phenotype with an enhanced migratory capacity (15) and the decreased expression of Ecadherin would be expected in these conditions (16). Epithelial cells undergoing EMT reorganize their cytoskeletons and transition into a spindle-like morphology. They have increased mesenchymal protein expression such as $\mathrm{N}$-cadherin, $\alpha$-smooth muscle actin and vimentin (17-20). EMT can be classified into three functionally distinct categories (21). Type II EMT is relevant in asthma and is involved in tissue repair and wound closure, via generation of a pool of mesenchymal cells that is required for tissue regeneration (22). Type II EMT can persist beyond the inflammatory process and lead to pathological fibrosis. Recently, the bronchial epithelium has been studied as a source of fibroblasts and myofibroblasts which are important players in airway remodeling in asthma (23). Chronic inflammation may lead to uncontrolled tissue repair by Type II EMT consequent to repeated damage of the epithelium by allergens, infections, allogenicity, cigarette smoke, etc. This can result in excessive production of ECM proteins by fibroblasts and myofibroblasts, ultimately leading to tissue fibrosis and remodeling. There is increasing evidence for the involvement of EMT in asthma, in vitro and in murine models $(4,23-26)$.
Transforming growth factor- $\beta 1$ (TGF- $\beta 1$ ) is a potent and well described inducer of EMT, and a profibrotic growth factor with immunoregulatory properties. Eosinophilic derived TGF- $\beta 1$ has been linked to fibrosis in asthmatic airways, and is a known pro-fibrotic factor in the airway wall of allergic (predominantly eosinophilic) asthmatics (27). Increased levels and expression of TGF- $\beta 1$ have been shown in BALF and in bronchial biopsies of asthmatics with a more severe form of disease (27-30). Evidence from patients with asthma suggests that TGF- $\beta 1$ protein and mRNA correlates with the thickness of subepithelial basement membrane $(29,30)$. In vitro studies have also shown that fibroblast to myofibroblast and epithelial to mesenchymal transitions can be induced by TGF- $\beta 1$ (31). Targeted expression of TGF- $\beta 1$ in newborn and adult rat lungs induces a dramatic fibrotic response with minimal inflammation. This response is characterized by extensive deposition of the extracellular matrix proteins collagen, fibronectin, and elastin, and by emergence of cells with the myofibroblast phenotype.

Neutrophils are central players in the inflammatory process present in asthma and have the capacity to produce TGF- $\beta 1$. Airway neutrophilia is associated with more severe airflow obstruction, lower lung function and thicker airway walls (6-8). Wenzel et al. showed that neutrophil numbers are increased in BALF collected from severe asthmatic patients but not in mild asthmatic or moderate asthmatic patients (32). The relationship between airflow obstruction and airway neutrophilia has also been reported by Shaw et al. in a group of 1100 asthma patients. They found that both neutrophilia and eosinophilia were associated with low prebronchodilator FEV1, but only neutrophilia was associated with low post-bronchodilator FEV1 (33).

These studies demonstrate that airway neutrophilia is a characteristic of severe asthma and suggest that neutrophils have a significant role in the airway narrowing of asthmatic patients. In addition to producing TNF- $\alpha$, IL-1 $\beta$, IL-3, IL-6, IL-8, and GM-CSF (34), neutrophils are known to produce TGF- $\beta 1$ (35). Interestingly, TGF$\beta 1$ can both recruit and activate neutrophils (36). It can also prolong neutrophil survival $(37,38)$. Chu et al. have reported that airway and blood neutrophils from both asthmatic and normal subjects can express and release TGF- $\beta 1$, and that culture supernatants from asthmatic peripheral blood neutrophils released significantly higher levels of TGF- $\beta 1$ than those from normal control subjects (39). Although these studies document accumulations of neutrophils in the airway walls of severe asthmatics, they also raise questions about the role these cells play in the process of airway remodeling. This has 
led us to consider the hypothesis that neutrophils induce EMT process via TGF- $\beta 1$, and thereby contribute to the pathophysiology of severe asthma. This study will investigate the neutrophil-epithelial cell interaction in the context of EMT and asthma using an in vitro system. Our results lead us to conclude that neutrophils may play a significant role in the development of airway remodeling and fibrosis in severe asthmatic airways as an inducer of EMT and an important source of TGF- $\beta 1$.

\section{Methods}

\section{Human bronchial epithelial cell isolation}

Normal primary human bronchial epithelial cells (NHBE) were purchased from LONZA (Walkersville, USA) or directly isolated from healthy human airways post-mortem. In the latter case, the lungs were kept on ice and processed within 24-48 h after surgery. Fresh human bronchial segments were obtained from the right middle lobe and cut longitudinally. "Strips" of epithelial cells were then identified using a light microscope and were gently detached from the bronchial segments. These tissue explants were allowed to adhere in a petri dish using the PneumaCult medium complemented with Penicillin $(10,000$ Unit $/ \mathrm{ml})$ Streptomycin $(10,000 \mu \mathrm{g} / \mathrm{ml})$ and Amphotericin B $(25 \mu \mathrm{g} / \mathrm{ml})$ and left to incubate at $37^{\circ} \mathrm{C}$. Within 1-3 weeks, cells started growing from the explants and populating the petri dish. No differences in the outcome of the experiments were observed using purchased NHBE vs bronchial epithelial cells isolated post-mortem.

\section{Human bronchial epithelial cell culture and treatment}

Bronchial epithelial cells were cultured in culture flasks using the bronchial epithelial cell culture medium PneumaCult (Stemcell Technologies, Vancouver, CA) complemented as described above. When a confluence of $75 \%$ was reached, the flask was washed with sterile PBS and the cells were detached by trypsinization. Cell counts were performed manually using a haemocytometer (a $0.4 \%$ Trypan blue solution was mixed with an equal volume of cell containing media), or automatically using an automated cell counter $(60 \mu \mathrm{m}$ tip). Both methods yielded similar results. Cells were seeded in 12 well plates at a density of 50,000 cells per well, or in 6 well plates at 100000 cells per well. The cells were then incubated with either fresh media containing TGF- $\beta 1(10 \mathrm{ng} / \mathrm{ml})$ (Bio-Rad, CA), $0.1-1.0 \times 10^{6}$ neutrophils $/ \mathrm{ml}$, or exposed to neutrophil-conditioned media (derived from $0.1-1.0 \times 10^{6}$ neutrophils $/ \mathrm{ml}$ ) for $48 \mathrm{~h}$, as below.

\section{Neutrophil isolation}

Peripheral venous blood was obtained from healthy nonasthmatic and severe asthmatic subjects. Severe asthmatic individuals had a forced expiratory volume at $1 \mathrm{~s}$ (FEV1) lower than $80 \%$ of vital capacity (VC) and poor symptom control (asthma control test scores $<20$ or asthma control questionnaire score $>1.5$ ) despite high doses of ICS or OCS. These patients had also experienced one or more severe exacerbations requiring hospitalization in the past year. Patient characteristics are shown in Table 1. Neutrophils were isolated from peripheral venous blood by column-free immunomagnetic separation using an EasySep ${ }^{\text {Tx }}$ Direct human neutrophil isolation Kit (Stemcell Technologies, Vancouver, CA.) The cells were suspended and cultured in enriched Roswell Park Memorial Institute 1640 medium (RPMI) (Life Technologies, Carlsbad, USA) without serum.

\section{Neutrophil-epithelial cell co-cultures}

Bronchial epithelial cells were cultured in 6- or 12-well plates until $60-70 \%$ cell confluence. Human neutrophils were then added to the culture (up to $1 \times 10^{6}$ neutrophils for 12-well plates). In preliminary experiments we determined that after $48 \mathrm{~h}$, only $34 \%$ of neutrophils were still viable, whereas after $24 \mathrm{~h}, 65 \%$ of the neutrophils were still viable. For this reason we decided to add human neutrophils to the culture and incubate for $24 \mathrm{~h}$. We then removed the neutrophils from the culture supernatant by centrifugation and the original medium

Table 1 Clinical characteristics of subjects included in the study

\begin{tabular}{lll}
\hline & Asthmatics & Non-asthmatics \\
\hline $\begin{array}{l}\text { Subjects (n) } \\
\text { Severity }\end{array}$ & 15 & 4 \\
$\quad$ Mild & $1 / 15$ & \\
$\quad$ Severe & $14 / 15$ & \\
Female / Male (n) & $7 / 8$ & $3 / 1$ \\
Age & $51.8 \pm 11$ & $47.5 \pm 15$ \\
Ethnic group (n) & & \\
$\quad$ Caucasian & 11 & 4 \\
$\quad$ North indian/pakistan & 1 & \\
$\quad$ African descendant & 1 & \\
$\quad$ Asian & 1 & $67.25 \pm 13.4$ \\
Weight (kg) & $74.83 \pm 21.6$ & $1.64 \pm 0.03$ \\
Height (m) & $1.66 \pm 0.09$ & $3.07 \pm 0.45$ \\
FEV1 (I) & $2.5 \pm 0.77$ & $102 \pm 15.2$ \\
FEV1 (\%) & $79.7 \pm 22.2$ & $0.83 \pm 0.008$ \\
FEV/FVC & $0.70 \pm 0.12$ & \\
\hline
\end{tabular}


was added back to the epithelial cells for a further $24 \mathrm{~h}$, for a total of $48 \mathrm{~h}$.

\section{Epithelial cells cultured in neutrophil-conditioned medium and preparation of conditioned media}

Again bronchial epithelial cells were cultured in 6- or 12-well plates until 60-70\% cell confluence. Cells were then treated with neutrophil-conditioned medium (without neutrophils) to determine whether cell to cell contact was necessary for the induction of EMT. Neutrophil conditioned medium was obtained by culturing neutrophils $\left(0.1-1 \times 10^{6} / \mathrm{ml}\right)$ in serum-free RPMI for $24 \mathrm{~h}$. Supernatants were collected, and cells and debris were removed by centrifugation to obtain the conditioned media which was then used for experiments.

\section{Semi-quantitative RT-PCR}

Total RNA was isolated from cultured primary bronchial epithelial cells and purified using the Nucleospin RNA Kit (Takara Bio, Germany) following the manufacturer's instructions. After extraction, RNA concentrations and purity were measured by spectrophotometry using the Epoch Spectrophotometer System. 200 ng of RNA per sample was then reverse transcribed to cDNA using the Iscript reverse transcription kit (Bio-Rad, CA) and Nexus machine following the supplier's guidelines. cDNA was stored at $-20^{\circ} \mathrm{C}$ and remaining RNA at $-80^{\circ} \mathrm{C}$. All primers were purchased from Life Technology (Table 2). Reaction mix without cDNA was used as a negative control, and the human GAPDH gene was used as the housekeeping gene (Table 2). cDNA was subjected to PCR using the SsoAdvanced Universal Sybergreen Green Supermix PCR Master Mix (Bio-Rad) to amplify human transcripts of genes that are markers of the EMT process such as: E-cadherin, $\mathrm{N}$-cadherin, alpha smooth muscle actin and vimentin using their respective sense and

Table 2 Forward and reverse primers of EMT markers and their oligo sequences

\begin{tabular}{ll}
\hline Primer name & Oligo sequence (5' to 3') $^{\prime}$ \\
\hline GAPDH Forward & GAAGGTGAAGGTCGGGT \\
N-Cadherin Forward & GAAGATGGTGATGGGATTC \\
N-Cadherin Reverse & CTCCATGTGCCGGATAGC \\
E-Cadherin Forward & CGATTCACCAGAAGCCTCTAC \\
E-Cadherin Reverse & GCCGAGAGCTACACGTCA \\
Vimentin Forward & GACCGGTGCAATCTCAAA \\
Vimentin Reverse & GTTTCCCCTAAACCGCTAGG \\
aSMA Forward & AGCGAGAGTGGCAGAGGA \\
aSMA Reverse & CCGACCGAATGCAGAAGGA \\
\hline
\end{tabular}

antisense primers (Life Technologies) (Table 2). The PCR reaction was carried out in duplicates and according to the manufacturer's recommended thermal cycling protocol.

\section{Immunofluorescence}

Some of the isolated neutrophils were used to prepare slides for immunostaining by cytospin. Neutrophils were suspended in RPMI medium at 500,000 cells per millilitre and $80 \mu \mathrm{L}$ was used per slide. Neutrophils were then fixed with a $4 \%$ solution of paraformaldehyde for $20 \mathrm{~min}$, and the slides stored at $-20^{\circ} \mathrm{C}$. The Ventana DISCOVERY ULTRA automated slide preparation system was used to stain the neutrophils. The RUO DISCOVERY Universal protocol was applied where the primary antibody specific for human TGF- $\beta 1$ (MAB-240, R\&D Systems) at a 1:100 dilution was incubated for $60 \mathrm{~min}$ followed by fluorescently-tagged secondary antibodies (R\&D Systems). Cell nuclei were stained with DAPI and the slides were observed with an Olympus immunofluorescence microscope.

\section{Enzyme-linked immunosorbent assay (ELISA)}

ELISA was used to quantify TGF- $\beta 1$ in neutrophil conditioned medium and culture supernatants. Neutrophil-conditioned media were collected and centrifuged at $300 \times \mathrm{g}$ for $5 \mathrm{~min}$ at $4{ }^{\circ} \mathrm{C}$ to eliminate cells and cell debris. Supernatants were then collected and stored at $-80^{\circ} \mathrm{C}$. A TGF- $\beta 1$ ELISA kit purchased from R \& D systems (Minneapolis, USA) was used, according the manufacturer's protocol, to quantify protein amounts in the conditioned media. TGF- $\beta 1$ protein amounts in unconditioned medium were also measured to account for any small amounts that could be already present in the medium. In preliminary experiments, we measured TGF- $\beta 1$ with and without activation (adding $1 \mathrm{~N} \mathrm{HCl}$ ) in neutrophils from both asthmatics and non-asthmatics, we found no differences in TGF- $\beta 1$ levels. This suggests that TGF- $\beta 1$ was constantly being activated. As such, we believe we were measuring the active form of TGF- $\beta 1$ in our experiment.

\section{Analysis of epithelial morphology}

Images of live cell cultures were taken using light microscopy. Changes in epithelial cell morphology were then quantified using Image-J's image analysis tools. Superimposed cells were removed from the analysis as the borders of superimposed cells were very difficult to define. Cell shape measurements (roundness, Feret's diameter, aspect ratio) were obtained for all the individual cells, as well as an average per image. At least $3 \mathrm{im}$ ages were analyzed per condition. 
Neutrophil-epithelial cell co-cultures with anti-TGF- $\beta 1$ neutralizing antibody

Severe asthmatic neutrophils suspended in the co-culture medium were pre-treated with $20 \mu \mathrm{g} / \mathrm{mL}$ of anti-human TGF- $\beta 1$ antibody (MAB240, R\&D Systems) for $2 \mathrm{~h}$. Bronchial epithelial cells were then co-cultured with the neutrophils in the presence of anti-human TGF- $\beta 1$ neutralizing antibody $(20 \mu \mathrm{g} / \mathrm{mL})$ for $48 \mathrm{~h}$ as previously described. Total RNA was isolated and purified to study changes in EMT marker expression.

\section{Statistical analysis}

Standard statistical t-tests and one-way ANOVA were performed to test for statistical significance between data groups.

\section{Results}

Neutrophils affect the expression of EMT markers when co-cultured with epithelial cells

Peripheral blood neutrophils were efficiently isolated from non-asthmatic and severe asthmatic individuals (purity > 99\%) (Table 1). The cell viability was also obtained by trypan blue viability assay, at the time of isolation, and $12 \mathrm{~h}$, $24 \mathrm{~h}$ and $48 \mathrm{~h}$ post-isolation, the following percentages represent cell viability after these time points respectively: 98, 92, 65 and 34\%. Two types of cell culture were performed in this study using the peripheral blood neutrophils from non-asthmatic or severe asthmatic individuals. Neutrophil conditioned medium was obtained and used to treat primary epithelial cell cultures, or neutrophils were directly co-cultured with the epithelial cells.

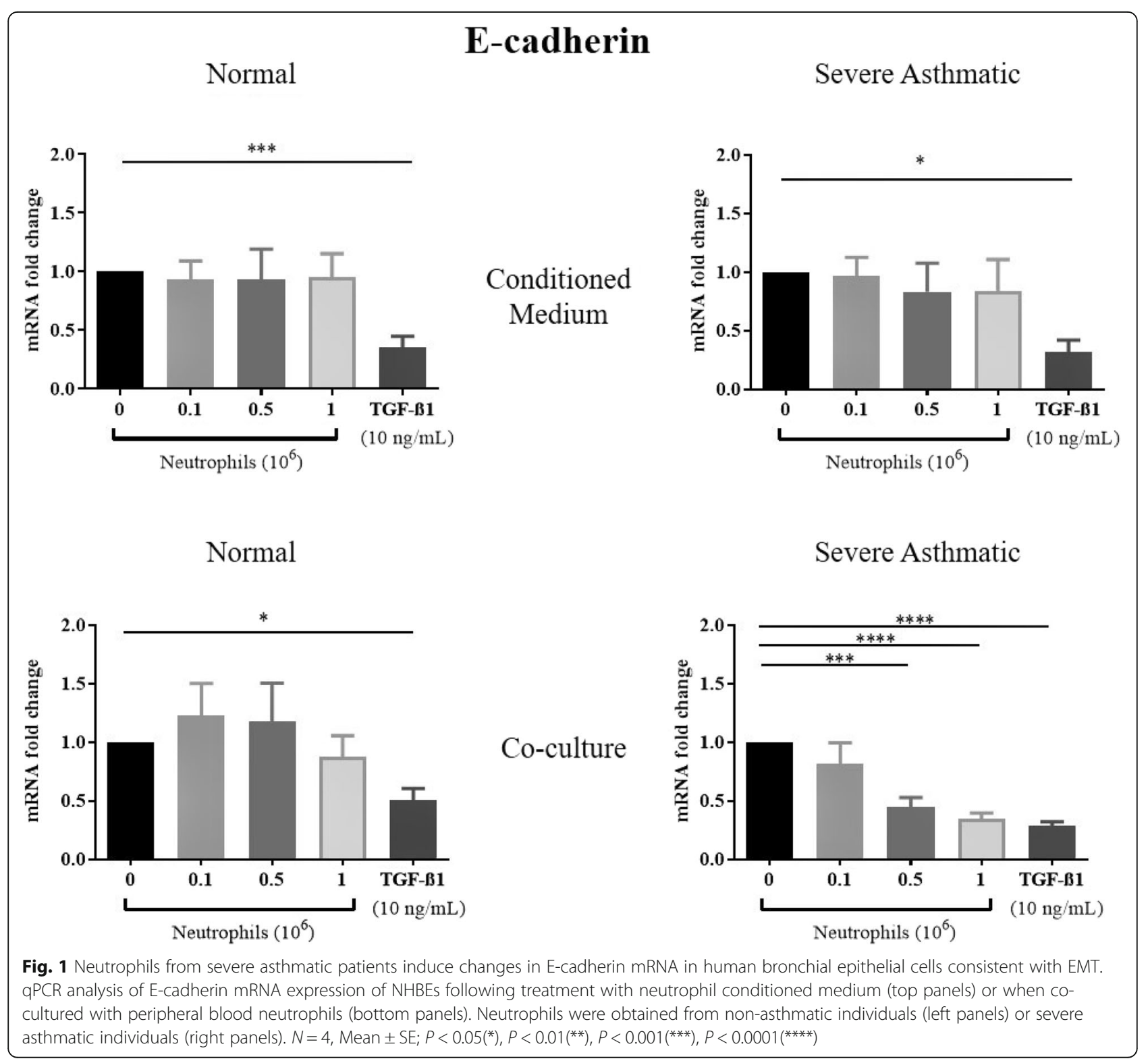


TGF- $\beta 1$ treatments of NHBE induced EMT, as shown by a significant reduction in mRNA expression of E-cadherin, and increased N-cadherin, $\alpha \mathrm{SMA}$ and vimentin mRNA expression (Figs. 1, 2, 3, 4). These results were consistent with previous studies showing that TGF- $\beta 1$ is a potent EMT inducer. We found that neutrophils from severe asthmatics induced a significant reduction in E-cadherin expression, and increased $\mathrm{N}$-cadherin, $\alpha \mathrm{SMA}$ and vimentin expression only when co-cultured with NHBEs, similar to the response induced by TGF- $\beta 1$ treatment (Figs. 1, 2, 3, 4). These changes are consistent with the EMT process and were not observed when NHBEs were treated with neutrophil conditioned medium (from both non-asthmatic and neutrophils from severe asthmatics). Although neutrophils from non-asthmatics and NHBE co-cultures did not induce significant changes in E-cadherin and vimentin mRNA expression, we did find a statistically significant increase in $\mathrm{N}$-cadherin and alpha smooth muscle actin expression in epithelial cells treated with the culture supernatant of neutrophils from severe asthmatics.

Epithelial cells undergo morphological changes when cocultured with neutrophils from severe asthmatic individuals

Epithelial cells undergoing EMT change in morphology. We quantified these morphological changes using three cell shape descriptors. Feret's diameter represents the total length of the cell and the aspect ratio is a measure of cell elongation (ratio of length to width). Cell

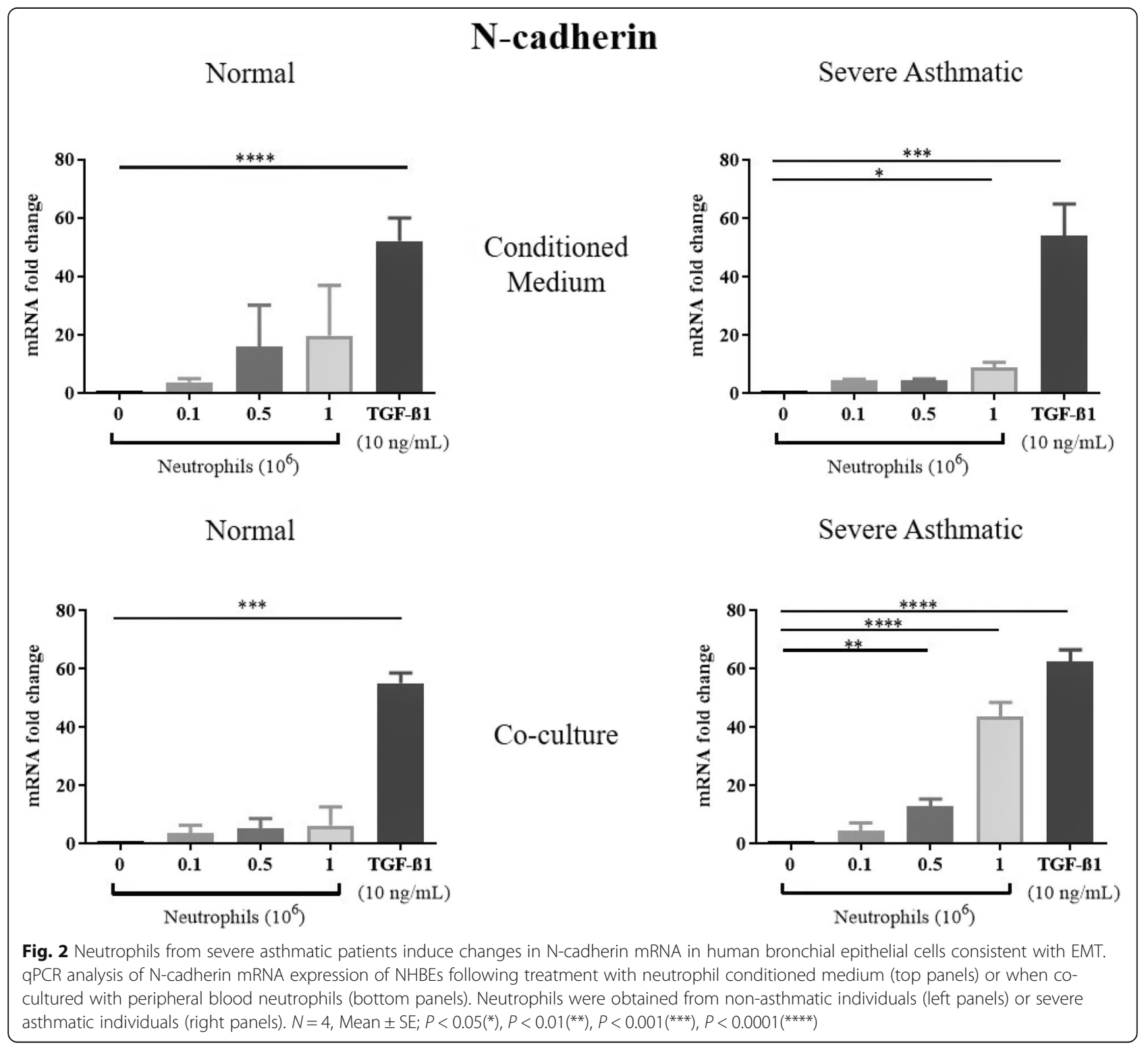




\section{Alpha smooth muscle actin}

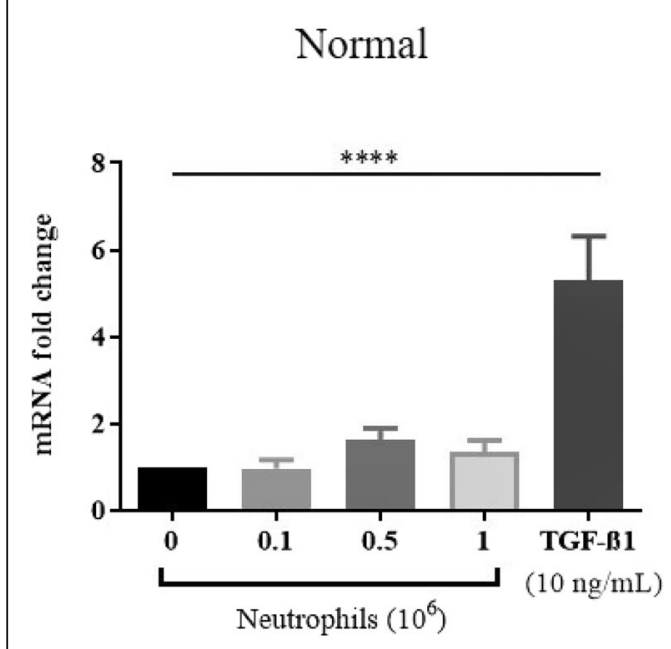

Normal

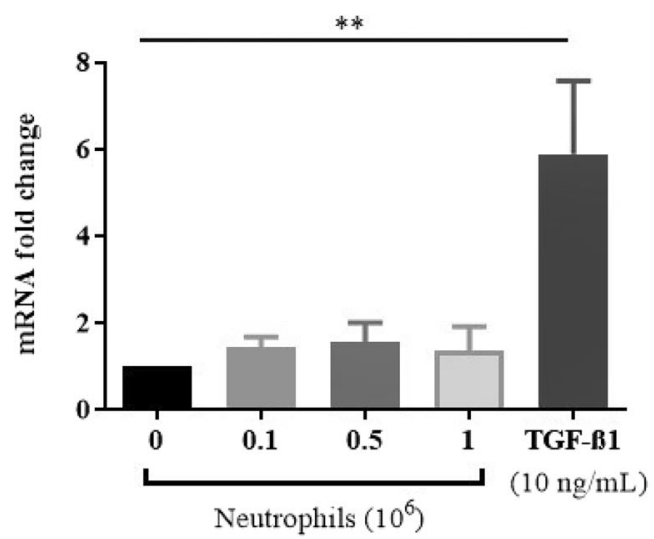

Severe Asthmatic

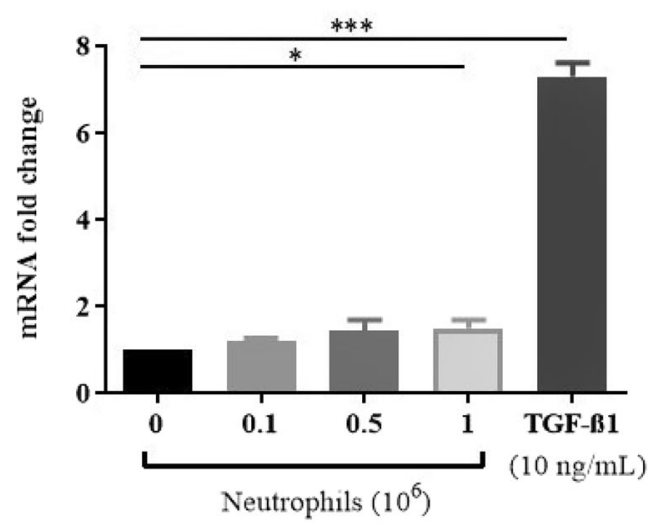

Severe Asthmatic

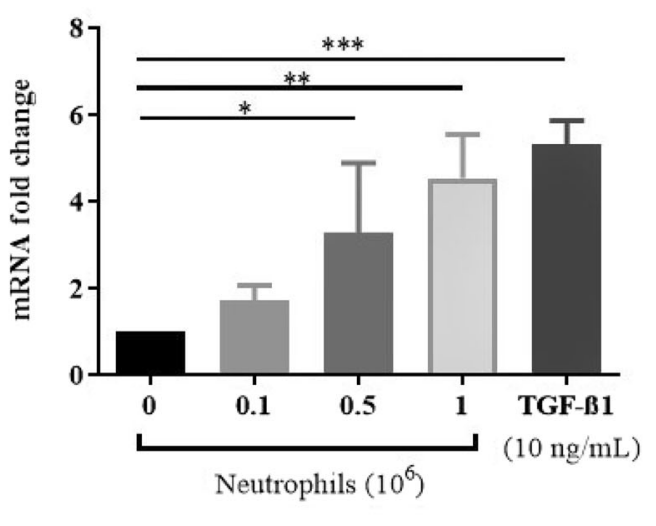

Fig. 3 Neutrophils from severe asthmatic patients induce changes in alpha smooth muscle actin mRNA in human bronchial epithelial cells consistent with EMT. qPCR analysis of Alpha smooth muscle actin mRNA expression of NHBEs following treatment with neutrophil conditioned medium (top panels) or when co-cultured with peripheral blood neutrophils (bottom panels). Neutrophils were obtained from non-asthmatic individuals (left panels) or severe asthmatic individuals (right panels). $N=4$, Mean $\pm \mathrm{SE} ; P<0.05\left(^{*}\right), P<0.01\left(^{* *}\right), P<0.001\left(^{(* *}\right), P<0.0001\left(^{* * * *}\right)$

roundness was also measured and averaged for each experimental condition.

TGF- $\beta 1$ treatment of NHBE resulted in significant morphological changes. Both average Feret's diameter and the average aspect ratio were increased from $48 \pm 5.6$ to $115 \pm$ 15 (A.U.) and from $1.6 \pm 0.051$ to $4.4 \pm 0.45$ (A.U.) respectively, consistent with cell elongation and EMT (Figs. 5, 6). Roundness was significantly decreased upon stimulation with TGF- $\beta 1$ from $0.5 \pm 0.026$ to $0.2 \pm 0.020$ (Fig. 6).

Consistent with our previous results, we found that only NHBEs which were co-cultured with neutrophils from severe asthmatics displayed significant changes in morphology. The average Feret's diameter and aspect ratio both significantly increased to $107 \pm 7.9$ and $4.2 \pm$
0.18 (A.U) respectively, and the roundness decreased to $0.4 \pm 0.019$ (Fig. 6).

\section{Neutrophils from severe asthmatic individuals increase} TGF- $\beta 1$ levels in medium when co-cultured with epithelial cells

TGF- $\beta 1$ is a pro-fibrotic factor in the airway wall of asthmatics and a potent inducer of EMT and is produced by neutrophils. We performed fluorescent staining of peripheral blood neutrophils using an anti-human TGF- $\beta 1$ antibody to confirm TGF- $\beta 1$ expression in these cells. In line with previous reports, we found that normal and neutrophils from severe asthmatics contained TGF- $\beta 1$ (Fig. 7a). 


\section{Vimentin}

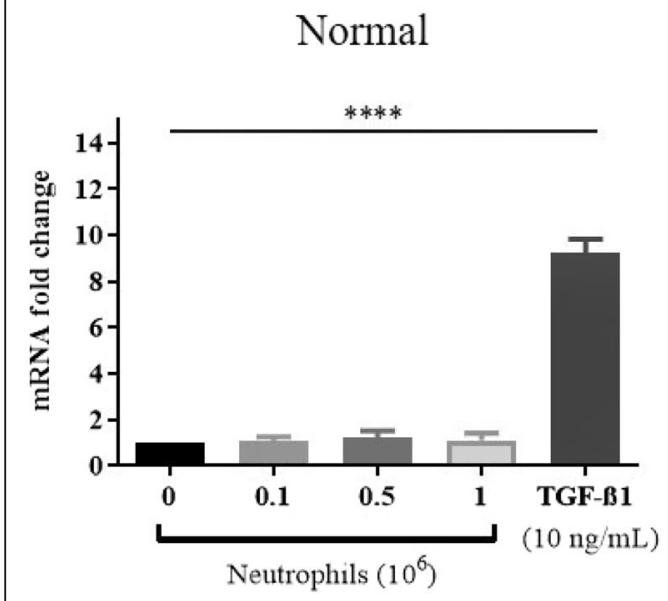

Normal

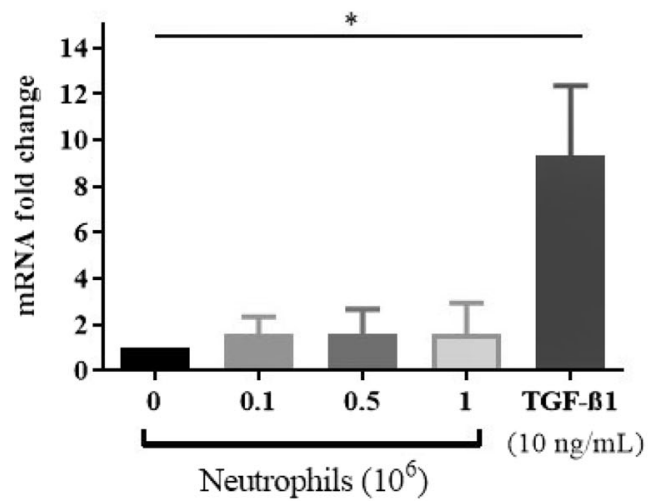

Severe Asthmatic

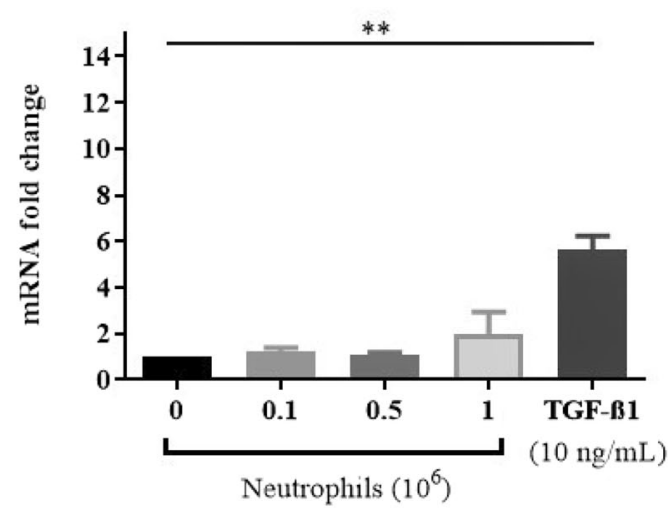

Severe Asthmatic

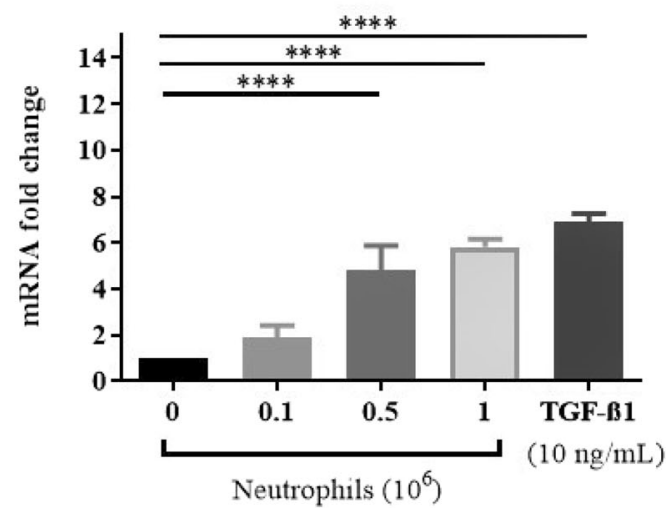

Fig. 4 Neutrophils from severe asthmatic patients induce changes in Vimentin mRNA in human bronchial epithelial cells consistent with EMT. qPCR analysis of Vimentin mRNA expression of NHBEs following treatment with neutrophil conditioned medium (top panels) or when cocultured with peripheral blood neutrophils (bottom panels). Neutrophils were obtained from non-asthmatic individuals (left panels) or severe asthmatic individuals (right panels). $N=4$, Mean \pm SE; $P<0.05\left({ }^{*}\right), P<0.01\left(^{* *}\right), P<0.001\left(^{(* *}\right), P<0.0001\left(^{* * * *}\right)$

We then measured TGF- $\beta 1$ protein levels by ELISA in neutrophil conditioned medium (non-asthmatic vs severe asthmatic) and in culture supernatants (Fig. 7b). We did not find a significant difference in TGF- $\beta 1$ between normal neutrophil conditioned medium and severe asthmatic neutrophil conditioned medium. In addition, culture supernatant collected following the treatment of NHBEs with neutrophil-conditioned medium did not show any differences in TGF- $\beta 1$ protein levels when the neutrophils were from severe asthmatic individuals. However, culture supernatant collected from the NHBEs-neutrophils from severe asthmatics coculture revealed increased amounts of TGF- $\beta 1$ ( $910 \pm$ $1.6 \mathrm{pg} / \mathrm{mL}$ ) compared to supernatant from co-cultures of NHBEs with normal neutrophils $(591 \pm 6 \mathrm{pg} / \mathrm{mL})$.
TGF- $\beta 1$ neutralization reduces the ability of neutrophils to induce EMT

To test whether TGF- $\beta 1$ was driving EMT in our experiment, we neutralized the cytokine using an anti-human TGF- $\beta 1$ antibody. We found that neutralizing TGF- $\beta 1$ reduced the ability of neutrophils from severe asthmatic patients to induce EMT in NHBEs (Fig. 8, $n=2$ ). This suggests that TGF- $\beta 1$ contributes to the induction of EMT, but also that there are other important factors/cytokines involved.

\section{Discussion}

Our results suggest that peripheral blood neutrophils from severe asthmatic subjects have the ability to induce EMT. The changes in EMT marker expression and the acquisition of a spindle shaped morphology observed 


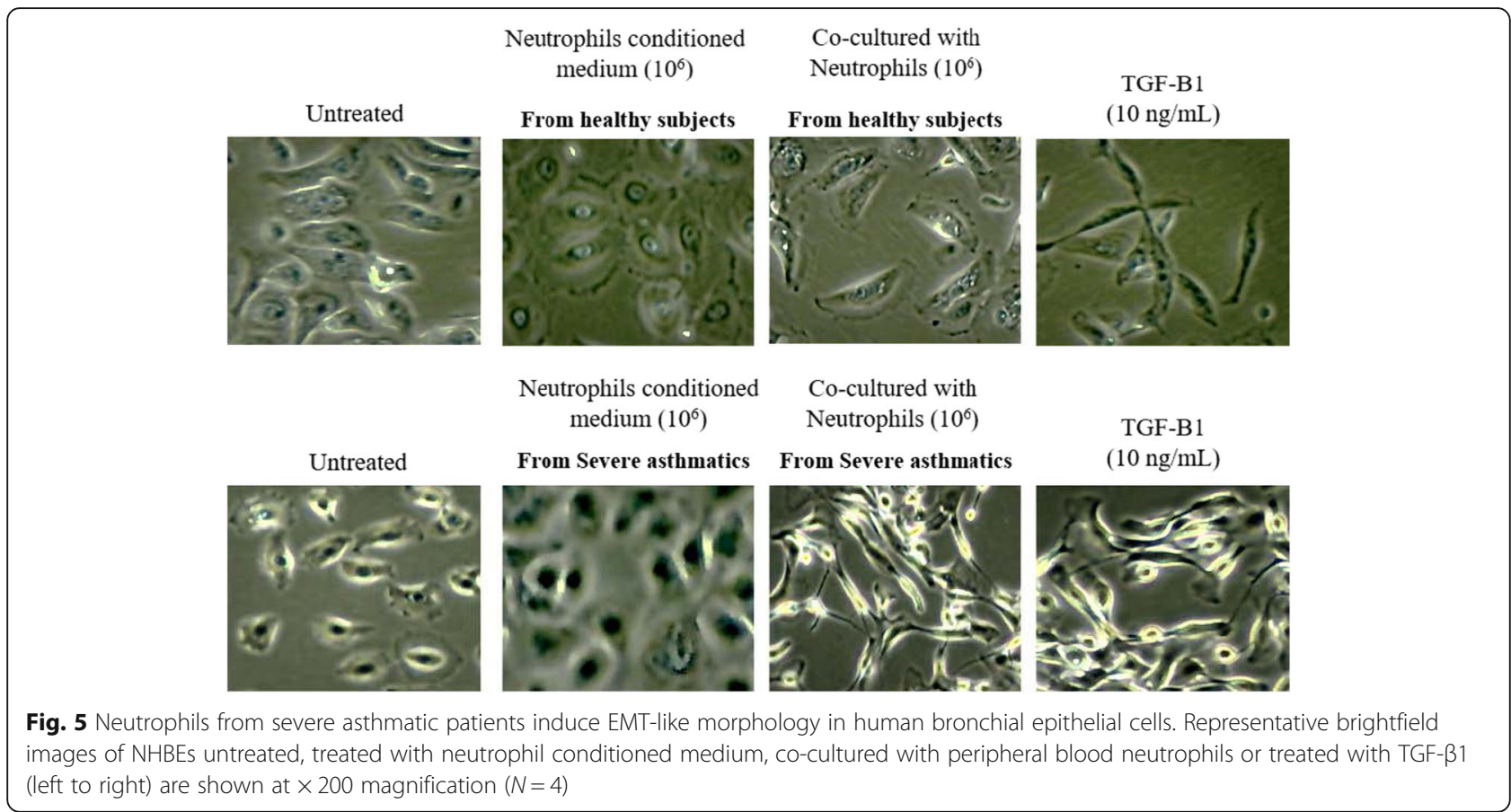

were consistent with the EMT process. These changes only occurred when epithelial cells were co-cultured with neutrophils or treated with TGF- $\beta 1$. Therefore, cell-cell contact seems to be required for the induction of EMT by neutrophils. Our data showing the importance of cell-cell contact is similar to those of Yasukawa et al. (40). This group showed that eosinophils are potent EMT inducers using a bronchial epithelial cell line and in vivo. Similarly, they found that EMT induction required direct cell-cell contact. In addition, they reported that eosinophils induce EMT in a TGF- $\beta 1$ dependent fashion.

In severe asthma patients, eosinophils are major TGF- $\beta 1$ producing cells (27). However, severe asthma patients with a neutrophil driven inflammation and without lung eosinophilia also may have remodeled airways. Neutrophils can mediate TGF- $\beta 1$ production in bronchial smooth muscle cells and dendritic cells via neutrophil elastase but are also TGF- $\beta 1$ producers themselves $(24,25)$. We confirmed the presence of cytoplasmic TGF- $\beta 1$ in neutrophils from nonasthmatic and severe asthmatic individuals, as previously reported (39). TGF- $\beta 1$ is a potent inducer of EMT and a profibrotic factor in the airway wall of asthmatics. It is increased in the airway walls of severe asthmatic individuals (27-30). This led us to consider the role of TGF- $\beta 1$ in the neutrophil mediated EMT induction in NHBE cells. TGF- $\beta 1$ was not significantly increased in neutrophil conditioned medium from neutrophils of severe asthmatics compared to neutrophils of non-asthmatic, indicating that the amounts of intrinsically released TGF- $\beta 1$ by normal and asthmatic neutrophils was similar. Our results contrast with those of
Chu et al. (39). Although they reported that the percentage of TGF- $\beta$ expressing neutrophils was similar between asthmatic and normal airway tissue, they found that peripheral blood neutrophils from asthmatic subjects spontaneously released more TGF- $\beta$ than those from non-asthmatic subjects. The amount of intrinsically released TGF- $\beta 1$ could be dependent on the isolation procedure, which can mechanically activate neutrophils. To minimize cell activation, we used an immunomagnetic isolation by negative selection.

The objective of our co-culture experiments was to have neutrophils and NHBE be in contact, allowing for potential crosstalk. Neutrophils have been shown to mediate TGF- $\beta 1$ production in bronchial smooth muscle cells and dendritic cells and could affect TGF- $\beta 1$ production in epithelial cells $(24,25)$. We found that TGF- $\beta 1$ levels were increased in the culture medium of neutrophils from severe asthmatics -NHBE co-cultures compared to that of neutrophil of non asthmatics-NHBE co-cultures. These findings suggest that neutrophils may be inducing EMT directly via TGF- $\beta 1$ or by signaling epithelial cells, which are also TGF- $\beta 1$ producers, to release the cytokine. The autocrine effect of TGF- $\beta 1$ in the context of EMT has been previously reported (41).

To test whether TGF- $\beta 1$ was the driver of EMT in our experiment, we neutralized the cytokine using an anti-human TGF- $\beta 1$ antibody. To account for the possible contribution of epithelial TGF- $\beta 1$, we pretreated bronchial epithelial cells with the neutralizing antibody before adding neutrophils. Our data, although preliminary, suggest that the EMT inducing ability of severe asthmatic neutrophils is reduced but not completely blocked by neutralizing TGF- $\beta 1$. This is 

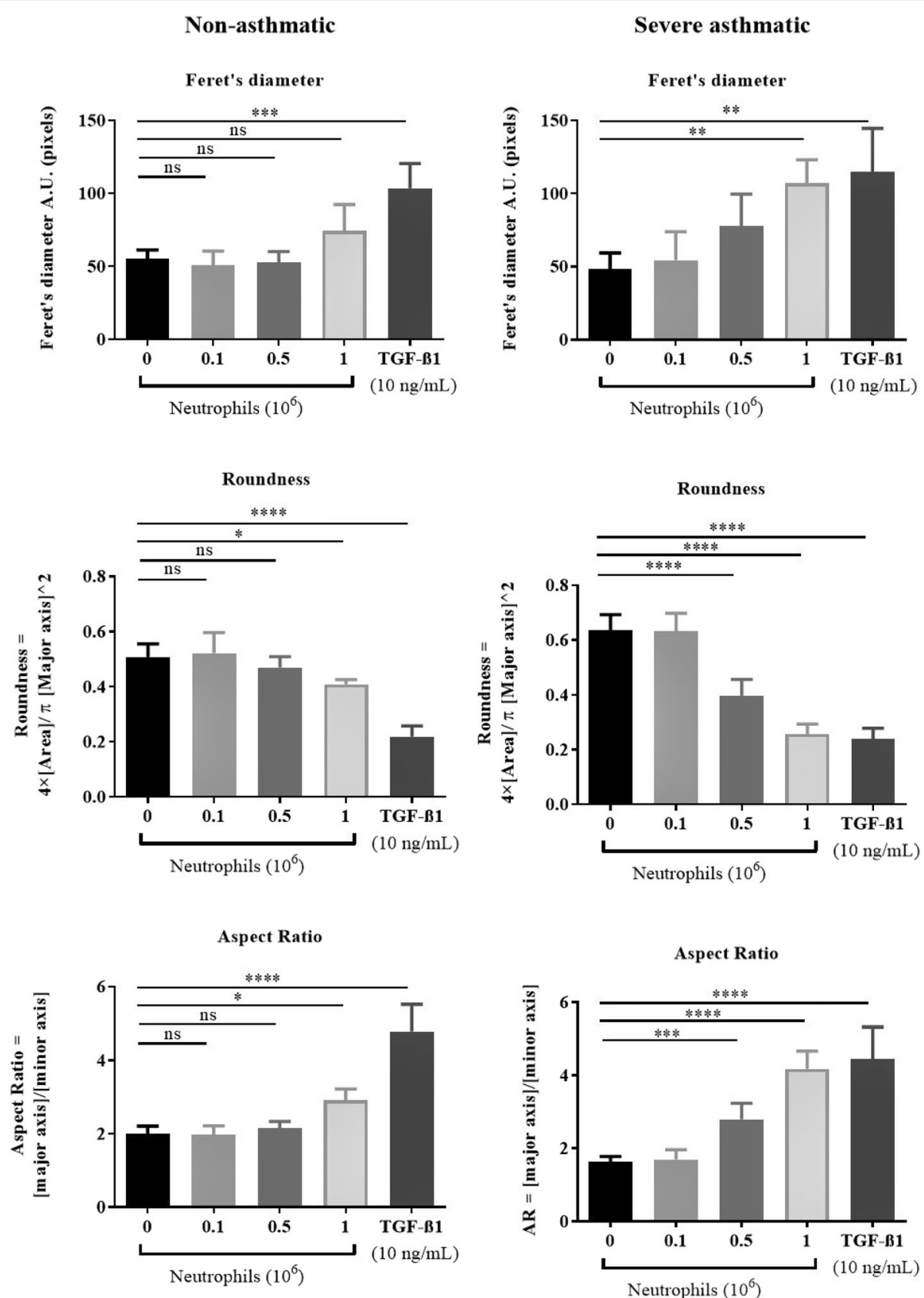

Fig. 6 Co-culture of NHBE with neutrophils from severe asthmatics induces a change in epithelial cell morphology. Quantification of epithelial cell shapes following co-culture with non-asthmatic (left panels) or severe asthmatic (right panels) peripheral blood neutrophils. All measurements were performed using Image J's shape analysis tools from 3 representative live cell culture images per independent experiment. $N=4, M e a n \pm S E$; $\left.P<0.05(*), P<0.011^{(*}\right), P<0.001\left(^{(* *}\right), P<0.00011^{(* * *)}$

consistent with the hypothesis that TGF- $\beta 1$ contributes to the induction of EMT, but that other factors are likely involved.

TGF- $\beta 1$ is the most potent and well-studied inducer of EMT. However, many other EMT inducers have been described. Those include epidermal growth factor (EGF), fibroblast growth factor (FGF), connective tissue growth factor, insulin-like growth factor-2 (IGF-II), interleukin-1 (IL-1) and hepatocyte growth factor (HGF) (42). Wnt ligands have also been shown to induce EMT. The effect of these mediators can be increased in response to damage to the basement membrane caused, for example, by MMPs. Furthermore, treating epithelial cells with EGF was shown to facilitate survival of cells undergoing EMT (43).

EMT can also occur in response to stresses in the cellular environment. Zhou et al. (44) have shown 


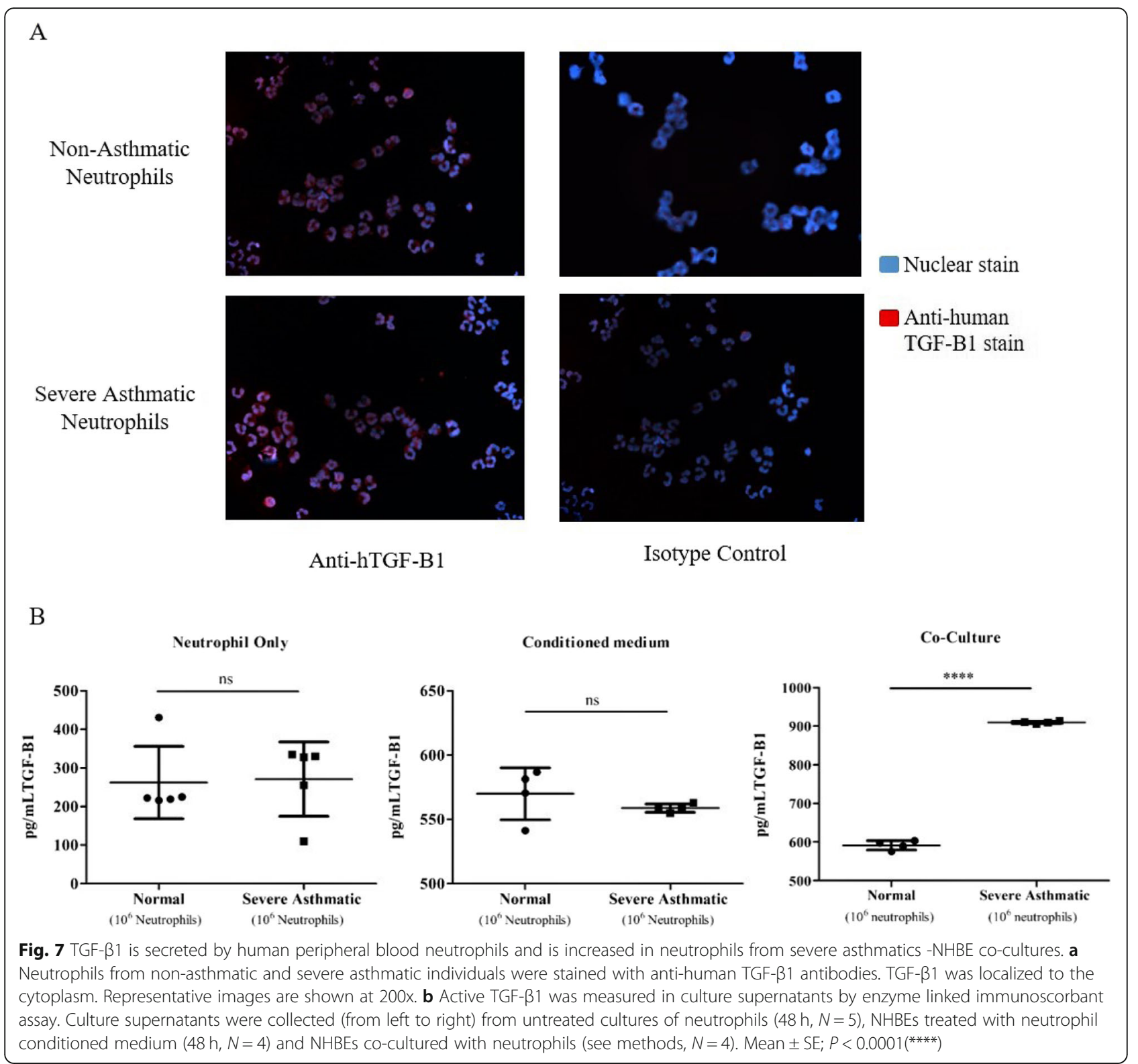

using an in vitro system, that reactive oxygen species were necessary to induce EMT by hypoxia in transformed and primary human, rat and mouse alveolar epithelial cells. Similar observations were made in renal tubular epithelial cells by Rhyu et al. (26). Neutrophils are known producers of ROS, and the latter could be an important mediator of the neutrophil induced differentiation we have reported. Therefore, it is important to consider the possibility that the induction of EMT observed is a result of a combination of factors and cellular environmental conditions, influenced by both the neutrophils and bronchial epithelial cells.

Our data suggests that TGF- $\beta 1$ is involved in the neutrophil mediated EMT induction. ROS, MMPs and changes in $\mathrm{pH}$ may be other important components of the neutrophil mediated EMT induction mechanism.

\section{Conclusions}

In this study, we showed that peripheral blood neutrophils from severe asthmatic patients can induce the EMT process when co-cultured with primary human bronchial epithelial cells. We also confirmed that neutrophils produce TGF- $\beta 1$, as previously reported. We did not find significant differences in TGF- $\beta 1$ secretion between neutrophils from healthy and severe asthmatics. However, we observed an increase in total TGF- $\beta 1$ amounts in the culture supernatant of severe asthmatic neutrophil-epithelial cell co-cultures, as 


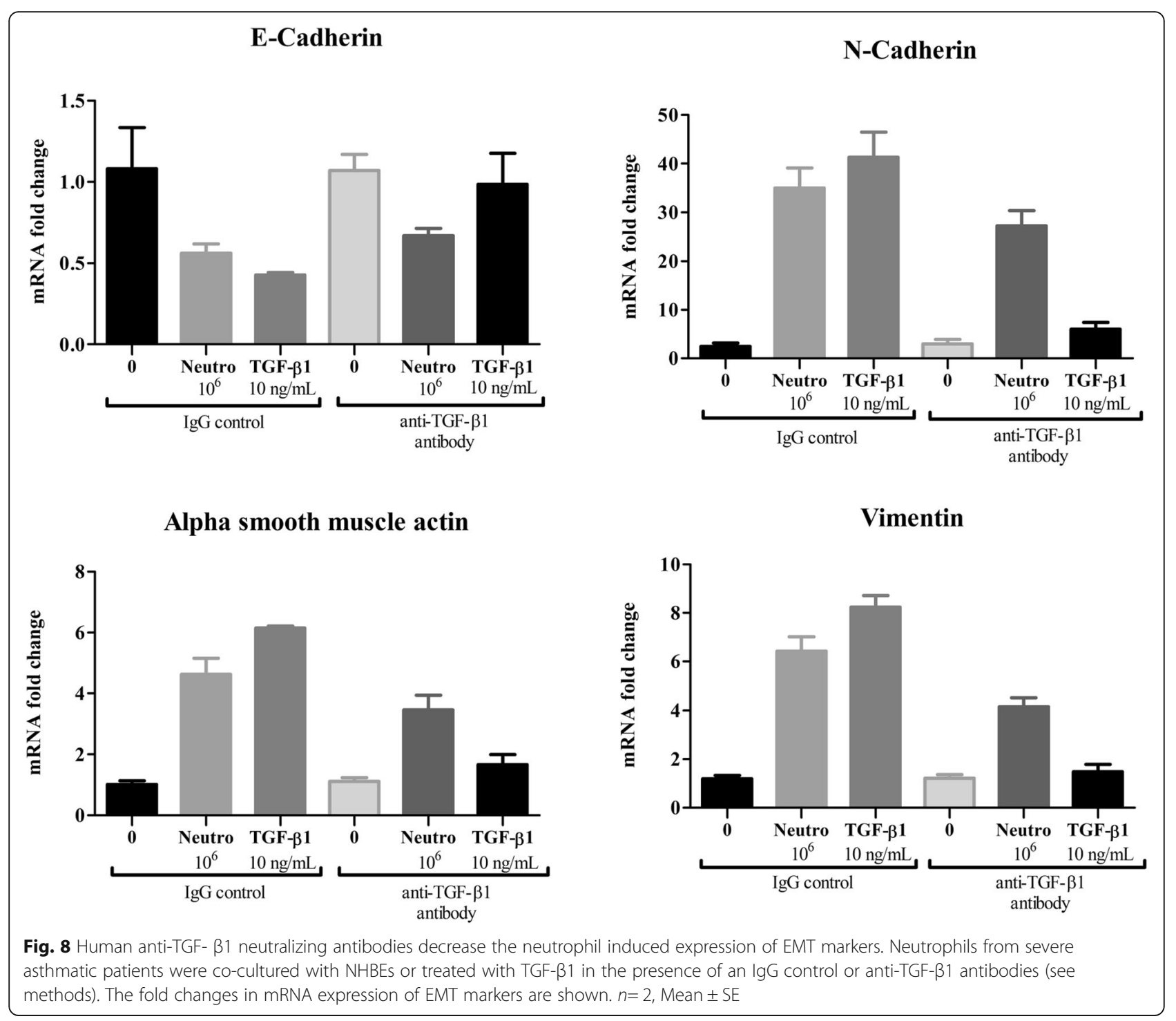

compared to normal neutrophil-epithelial cell cocultures. Blocking TGF- $\beta 1$ modified the process of EMT. These findings suggest that neutrophils contribute to the pathophysiology of asthma by inducing EMT in bronchial epithelial cells. These data support the importance of neutrophils in contributing to airway remodeling in asthma.

\section{Abbreviations}

ASM: Airway smooth muscle; BALF: Bronchoalveolar lavage fluid; ECM: Extracellular matrix; EGF: Epidermal growth factor; EMT: EpithelialMesenchymal transition; FEV (1): Forced expiratory volume at $1 \mathrm{~s}$; HGF: Hepatocyte growth factor; ICS: Inhaled corticosteroids; MMP: Matrix metalloproteinases; ROS: Reactive oxygen species; TGF- $\beta$ : Transforming growth factor-beta; TH2: T-helper type 2; a-SMA: A-smooth muscle actin

\section{Acknowledgments}

We would like to thank C. Fugere who provided and cared for the patients involved in this study. We would also like to acknowledge the valuable inputs of V. Narayanan and A. Panariti during the cell culture system setup and experiments.
Authors' contributions

AH completed all experimental results and analysis, he also drafted this article. MG, MP, ZA and AM participated in the revision and preparation for article submission. SA contributed to the immunofluorescence experiments in the study. DE and CB were advisors throughout the course of the study. $\mathrm{RO}$ was co-investigator of this project and aided in the recruitment of patients. ML and QH were supervisor and co-supervisor of this study and were involved in the project and experimental design. All authors read and approved the final manuscript.

\section{Funding}

This research was funded by the Richard and Edith Strauss Foundation.

Availability of data and materials

All data generated or analysed during this study are available from the corresponding author on reasonable request.

\section{Ethics approval and consent to participate}

Lung epithelial cells were isolated from lungs obtained by the International Institute for the Advancement of Medicine. Neutrophils were isolated from the blood of healthy and asthmatic donors where all subjects gave written consent and this research was approved by the McGill University Health Center Ethics Review Board. 


\section{Consent for publication}

Not applicable

\section{Competing interests}

$A H, M G, M P, Z A, A M, S A, C B, D E, Q H$ and $M L$ declare that they have no competing interests. $\mathrm{RO}$ received fees for lectures and as a consultant on advisory boards for Astra Zeneca, Boehringer-Ingelheim, Glaxo Smith Kline, Merck Frosst, Novartis, Sanofi and Teva and has also received funding for research from Astra Zeneca, Glaxo Smith Kline, Chiesi, Sanofi and Boston Scientific.

\section{Author details}

'Translational Research in Respiratory Diseases, Meakins-Christie Laboratories, Research Institute of the McGill University Health Centre, 1001 Boulevard Décarie, Montréal, QC H4A 3J1, Canada. 'Faculty of Medicine, McGill University, Montréal, Canada. ${ }^{3}$ College of Medicine, University of Sharjah, Sharjah, United Arab Emirates.

Received: 23 April 2019 Accepted: 11 September 2019 Published online: 29 October 2019

\section{References}

1. Trejo Bittar HE, Yousem SA, Wenzel SE. Pathobiology of severe asthma. Annu Rev Pathol. 2015;10:511-45.

2. Fahy JV. Type 2 inflammation in asthma [mdash] present in most, absent in many. Nat Rev Immunol. 2015;15(1):57-65.

3. Wenzel S. Severe asthma: from characteristics to phenotypes to endotypes. Clin Exp Allergy. 2012;42(5):650-8.

4. Holgate ST, Polosa R. The mechanisms, diagnosis, and management of severe asthma in adults. Lancet. 2006;368(9537):780-93.

5. Wenzel SE, Schwartz LB, Langmack EL, Halliday JL, Trudeau JB, Gibbs RL, et al. Evidence that severe asthma can be divided pathologically into two inflammatory subtypes with distinct physiologic and clinical characteristics. Am J Respir Crit Care Med. 1999;160(3):1001-8.

6. Green R, Brightling C, Woltmann G, Parker D, Wardlaw A, Pavord I. Analysis of induced sputum in adults with asthma: identification of subgroup with isolated sputum neutrophilia and poor response to inhaled corticosteroids. Thorax. 2002:57(10):875-9.

7. Woodruff PG, Khashayar R, Lazarus SC, Janson S, Avila P, Boushey HA, et al Relationship between airway inflammation, hyperresponsiveness, and obstruction in asthma. J Allergy Clin Immunol. 2001;108(5):753-8.

8. Gupta S, Siddiqui S, Haldar P, Raj JV, Entwisle JJ, Wardlaw AJ, et al. Qualitative analysis of high-resolution CT scans in severe asthma. CHEST Journal. 2009;136(6):1521-8.

9. James AL, Maxwell PS, Pearce-Pinto G, Elliot JG, Carroll NG. The relationship of reticular basement membrane thickness to airway wall remodeling in asthma. Am J Respir Crit Care Med. 2002;166(12):1590-5.

10. Naylor B. The shedding of the mucosa of the bronchial tree in asthma. Thorax. 1962;17(1):69-72.

11. Carroll N, Elliot J, Morton A, James A. The Strudure of large and small Airways in Nonfatal and Fatal Asthma. Am Rev Respir Dis. 1993;147:405-10.

12. Aikawa T, Shimura S, Sasaki H, Ebina M, Takishima T. Marked goblet cell hyperplasia with mucus accumulation in the airways of patients who died of severe acute asthma attack. Chest. 1992:101(4):916-21.

13. Tanaka H, Yamada G, Saikai T, Hashimoto M, Tanaka S, Suzuki K, et al. Increased airway vascularity in newly diagnosed asthma using a high-magnification bronchovideoscope. Am J Respir Crit Care Med. 2003;168(12):1495-9.

14. Aysola RS, Hoffman EA, Gierada D, Wenzel S, Cook-Granroth J, Tarsi J, et al. Airway remodeling measured by multidetector $C T$ is increased in severe asthma and correlates with pathology. CHEST. 2008;134(6):1183-91.

15. Xu J, Lamouille S, Derynck R. TGF- $\beta$-induced epithelial to mesenchymal transition. Cell Res. 2009;19(2):156-72.

16. Lee JM, Dedhar S, Kalluri R, Thompson EW. The epithelial-mesenchymal transition: new insights in signaling, development, and disease. J Cell Biol. 2006;172(7):973-81.

17. Vandewalle C, Comijn J, De Craene B, Vermassen P, Bruyneel E, Andersen H, et al. SIP1/ZEB2 induces EMT by repressing genes of different epithelial cellcell junctions. Nucleic Acids Res. 2005;33(20):6566-78.

18. Ikenouchi J, Matsuda M, Furuse M, Tsukita S. Regulation of tight junctions during the epithelium-mesenchyme transition: direct repression of the gene expression of claudins/occludin by snail. J Cell Sci. 2003;116(10):1959-67.
19. Chunhacha P, Sriuranpong V, Chanvorachote P. Epithelial-mesenchymal transition mediates anoikis resistance and enhances invasion in pleural effusion-derived human lung cancer cells. Oncol Lett. 2013;5(3):1043-7.

20. Ullmann U, Gilles C, Sermon K, De Rycke M, Van de Velde H, Van Steirteghem A, et al. Epithelial-mesenchymal transition process in human embryonic stem cells cultured in feeder-free conditions. Mol Hum Reprod. 2007;13(1):21-32.

21. Kovacic JC, Mercader N, Torres M, Boehm M, Fuster V. Epithelial-to-mesenchymal and endothelial-to-mesenchymal transition. Circulation. 2012;125(14):1795-808.

22. Zeisberg M, Shah AA, Kalluri R. Bone morphogenic protein-7 induces mesenchymal to epithelial transition in adult renal fibroblasts and facilitates regeneration of injured kidney. J Biol Chem. 2005;280(9):8094-100.

23. Pain M, Bermudez O, Lacoste P, Royer P-J, Botturi $K$, Tissot $A$, et al. Tissue remodelling in chronic bronchial diseases: from the epithelial to mesenchymal phenotype. Eur Respir Rev. 2014;23(131):118-30.

24. Lee $K-Y$, Ho S-C, Lin H-C, Lin S-M, Liu C-Y, Huang C-D, et al. Neutrophilderived elastase induces TGF- $\beta 1$ secretion in human airway smooth muscle via NF-kB pathway. Am J Respir Cell Mol Biol. 2006:35(4):407-14.

25. Maffia PC, Zittermann SE, Scimone ML, Tateosian N, Amiano N, Guerrieri D, et al. Neutrophil elastase converts human immature dendritic cells into transforming growth factor- $\beta 1$-secreting cells and reduces allostimulatory ability. Am J Pathol. 2007:171(3):928-37.

26. Rhyu DY, Yang Y, Ha H, Lee GT, Song JS, S-t U, et al. Role of reactive oxygen species in TGF- $\beta 1$-induced mitogen-activated protein kinase activation and epithelial-mesenchymal transition in renal tubular epithelial cells. J Am Soc Nephrol. 2005;16(3):667-75.

27. Minshall EM, Leung DY, Martin RJ, Song YL, Cameron L, Ernst $P$, et al. Eosinophil-associated TGF- 31 mRNA expression and airways fibrosis in bronchial asthma. Am J Respir Cell Mol Biol. 1997;17(3):326-33.

28. Chu HW, Halliday JL, Martin RJ, Leung DY, Szefler SJ, Wenzel SE. Collagen deposition in large airways may not differentiate severe asthma from milder forms of the disease. Am J Respir Crit Care Med. 1998:158(6):1936-44.

29. Vignola AM, Chanez P, Chiappara G, Merendino A, Pace E, Rizzo A, et al. Transforming growth factor- $\beta$ expression in mucosal biopsies in asthma and chronic bronchitis. Am J Respir Crit Care Med. 1997;156(2):591-9.

30. Redington AE, Madden J, Frew AJ, Djukanovic R, Roche WR, Holgate ST, et al. Transforming growth factor- $\beta 1$ in asthma: measurement in bronchoalveolar lavage fluid. Am J Respir Crit Care Med. 1997:156(2):642-7.

31. Hackett T-L, Warner SM, Stefanowicz D, Shaheen F, Pechkovsky DV, Murray $L A$, et al. Induction of epithelial-mesenchymal transition in primary airway epithelial cells from patients with asthma by transforming growth factor- $\beta 1$. Am J Respir Crit Care Med. 2009;180(2):122-33.

32. Wenzel SE, Szefler SJ, Leung DY, Sloan SI, Rex MD, Martin RJ. Bronchoscopic evaluation of severe asthma: persistent inflammation associated with high dose glucocorticoids. Am J Respir Crit Care Med. 1997;156(3):737-43.

33. Shaw DE, Berry MA, Hargadon B, McKenna S, Shelley MJ, Green RH, et al. Association between neutrophilic airway inflammation and airflow limitation in adults with asthma. CHEST. 2007;132(6):1871-5.

34. Cassatella MA. The production of cytokines by polymorphonuclear neutrophils. Immunol Today. 1995;16(1):21-6.

35. Grotendorst GR, Smale G, Pencev D. Production of transforming growth factor beta by human peripheral blood monocytes and neutrophils. J Cell Physiol. 1989:140(2):396-402.

36. Reibman J, Meixler S, Lee TC, Gold LI, Cronstein BN, Haines KA, et al. Transforming growth factor beta 1, a potent chemoattractant for human neutrophils, bypasses classic signal-transduction pathways. Proc Natl Acad Sci. 1991;88(15):6805-9.

37. Lagraoui M, Gagnon L. Enhancement of human neutrophil survival and activation by TGF-beta 1. Cell Mol Biol (Noisy-le-Grand, France). 1997;43(3):313-8

38. Fava RA, Olsen NJ, Postlethwaite AE, Broadley KN, Davidson J, Nanney L, et al. Transforming growth factor b1 (TGF-b1) induced neutrophil recruitment to synovial tissues: implications for TGF-b-driven synovial inflammation and hyperplasia. J Exp Med. 1991;173:1121-32.

39. Chu HW, Trudeau JB, Balzar S, Wenzel SE. Peripheral blood and aimay tissue expression of transforming growth factor $\beta$ by neutrophils in asthmatic subjects and normal control subjects. J Allergy Clin Immunol. 2000;106(6):1115-23.

40. Yasukawa A, Hosoki K, Toda M, Miyake Y, Matsushima Y, Matsumoto T, et al. Eosinophils promote epithelial to mesenchymal transition of bronchial epithelial cells. PLoS One. 2013;8(5):e64281.

41. Larocca C, Cohen JR, Fernando RI, Huang B, Hamilton DH, Palena C. An autocrine loop between TGF- $\beta 1$ and the transcription factor brachyury 
controls the transition of human carcinoma cells into a mesenchymal phenotype. Mol Cancer Ther. 2013;12(9):1805-15.

42. Willis BC, Borok Z. TGF- $\beta$-induced EMT: mechanisms and implications for fibrotic lung disease. Am J Phys Lung Cell Mol Phys. 2007;293(3):L525-L34.

43. Docherty NG, O'Sullivan OE, Healy DA, Murphy M, O'Neill AJ, Fitzpatrick $J M$, et al. TGF- $\beta$ 1-induced EMT can occur independently of its proapoptotic effects and is aided by EGF receptor activation. Am J Physiol Renal Physiol. 2006;290(5):F1202-F12.

44. Zhou G, Dada LA, Wu M, Kelly A, Trejo H, Zhou Q, et al. Hypoxia-induced alveolar epithelial-mesenchymal transition requires mitochondrial ROS and hypoxiainducible factor 1. Am J Phys Lung Cell Mol Phys. 2009;297(6):L1120-L30.

\section{Publisher's Note}

Springer Nature remains neutral with regard to jurisdictional claims in published maps and institutional affiliations.

Ready to submit your research? Choose BMC and benefit from:

- fast, convenient online submission

- thorough peer review by experienced researchers in your field

- rapid publication on acceptance

- support for research data, including large and complex data types

- gold Open Access which fosters wider collaboration and increased citations

- maximum visibility for your research: over $100 \mathrm{M}$ website views per year

At $\mathrm{BMC}$, research is always in progress.

Learn more biomedcentral.com/submissions 